\title{
Differential Diagnosis and Treatment Options for Xanthogranulomatous Cholecystitis
}

\author{
Yunfeng Cui Hongtao Zhang Erpeng Zhao Naiqiang Cui Zhonglian Li \\ Department of Surgery, Tianjin Nankai Hospital, Nankai Clinical School of Medicine, Tianjin Medical University, Tianjin, China
}

\section{Key Words \\ Xanthogranulomatous cholecystitis $\cdot$ Coexisting gallbladder cancer $\cdot$ Tumor marker $\cdot$ Radiological findings . Open surgery $\cdot$ Laparoscopic cholecystectomy}

\begin{abstract}
Objective: To describe the differential diagnosis and treatment options for xanthogranulomatous cholecystitis (XGC), the presentations and management of 68 patients were described. Subjects and Methods: Demographical and clinical data from 68 cases of XGC treated between January 2004 and January 2010 were analyzed. Clinical characteristics, radiological and surgical findings, histopathological features and postoperative recoveries were recorded. Clinical features of laparoscopic cholecystectomy versus open surgery and XGC versus gallbladder (GB) cancer were compared. $\boldsymbol{R} \boldsymbol{e}$ sults: The CA19-9 levels of XGC and coexisting GB cancer were significantly different $(p=0.0034)$. In radiological findings, focal thickening of the GB wall was more frequent in coexisting GB cancer, early enhancement of the GB was observed more often in coexisting GB cancer, and lymph node enlargement was seen more often in coexisting GB cancer $(p<0.05)$. There were also significant differences between laparoscopic and open surgery for CA19-9, intramural hypoattenuated nodule, pericholecystic invasion, lymph node enlargement and maximum thickness, focal thickening, heterogeneous enhancement and early enhancement of the GB
\end{abstract}

wall $(p<0.05)$. These findings were confirmed by multivariate analysis. Conclusions: Ultrasound, computed tomography scan and intraoperative frozen section were the helpful modalities for XGC diagnosis. CA19-9 (>37 kU/l), pericholecystic invasion, lymph node enlargement $(>10 \mathrm{~mm})$, and focal thickening and early enhancement of the GB wall were the criteria for open surgery. In some selected cases, laparoscopic cholecystectomy was preferable.

Copyright $\odot 2012$ S. Karger AG, Basel

\section{Introduction}

Xanthogranulomatous cholecystitis (XGC) is a rare condition of cholecystitis with intense inflammation [1]. It can cause asymmetrical thickening of the gallbladder (GB) wall and demonstrate a tendency to form nodules. The disease is benign but locally invasive and may involve adjacent organs such as the liver, duodenum, colon, and common bile duct. Involvement by the inflammatory process can macroscopically resemble carcinoma of the GB [2-5]. It is characterized by distinct pathological findings like fat-laden macrophages and foamy histiocytes and is associated with severe fibrosis. Gallstones, biliary stasis, and chronic infection may be possible etiological factors [6-8]. The XGC was first reported and named by McCoy et al. [9]. With a low incidence of $0.7-13.2 \%$ of all inflammatory diseases of the GB, it occurs mostly in

\section{KARGER}

Fax +4161306 1234

E-Mail karger@karger.ch

www.karger.com
(C) 2012 S. Karger AG, Basel

$1011-7571 / 13 / 0221-0018 \$ 38.00 / 0$

Accessible online at:

www.karger.com/mpp
Zhonglian Li

Department of Surgery, Tianjin Nankai Hospital

Nankai Clinical School of Medicine, Tianjin Medical University

122 Sanwei Road, Nankai District, Tianjin 300100 (China)

E-Mail zhonglianli@yeah.net 
middle-aged and elderly persons $[10,11]$. In some cases, XGC may be mistaken for malignancy, and it sometimes has coexistent GB cancer [12]. The frequency of the coexistence of these two lesions is approximately $10 \%$ in Japan and the USA $[13,14]$.

To contribute to the available experience, we report data of the diagnosis and treatment of 68 patients with XGC. The study involved the use of diagnostic techniques, their impact on surgical indication and the results of surgical treatment and follow-up.

\section{Subjects and Methods}

The clinical records of 29,875 patients who had undergone biliary operations in Tianjin Nankai Hospital between January 2004 and January 2010 were reviewed and 68 patients were identified as having a histopathological diagnosis of XGC. The patient records during this period were searched electronically and, if the diagnosis after surgery was XGC, the detailed medical record was checked manually. Details regarding operative approach and pathology were abstracted from the operative and pathological reports.

All patients underwent ultrasonography and computed tomography (CT) preoperatively. The surgical procedures included open cholecystectomy, biliary tract exploration, partial hepatic wedge resection, regional lymphadenectomy and laparoscopic cholecystectomy.

Demographic details, symptoms and signs, investigations, operative details, complications and follow-ups were evaluated. All patients were seen in the outpatient department within 3 months of initial surgery and every 6 months thereafter. Patients were clinically examined, and liver function tests and ultrasound study were evaluated for each follow-up visit. The study was performed after approval was granted by the Ethics Committee of Tianjin Nankai Hospital.

\section{Statistical Analysis}

Data were analyzed by using SPSS 16 (version 20.0.0). The $\chi^{2}$ test, Fisher's exact test and Student's t test were used to compare differences between the data. Multivariable logistic regression analysis by binary logistic regression was used to evaluate factors that favored the diagnosis of XGC with GB cancer and features for open surgery. The validation was performed by the Hosmer-Lemeshow test. A p value $<0.05$ indicated statistical significance.

\section{Results}

The demographics and general clinical features of the patients are shown in table 1 . The incidence of XGC was approximately $0.2 \%$ of inflammatory biliary diseases of this period. Of the 68 cases, $6(8.8 \%)$ were proven to be GB cancer by histological section after surgery. The CA19-9 levels of XGC and coexistent GB cancer were significantly different $(\mathrm{p}=0.0034)$. There were no signifi-
Table 1. Demographics and clinical features of all patients who underwent treatment

Item

Patients, $\mathrm{n}$

Demographic characteristics

Mean age, years

Sex, F/M

$62.6[20-83]$

$26 / 32$

Symptoms and signs

Pain

$48(70.6)$

Fever

Jaundice

$19(27.9)$

$13(19.1)$

Associated diseases

Hyperlipidemia $20(29.4)$

Hypertension

$12(17.6)$

Diabetes mellitus type 2

$5(7.4)$

Tumor markers

CEA (positive)

$12(5.9)$

CA19-9 (>37 kU/l)

$28(41.2)$

Radiologic findings (ultrasound and CT)

Gallstone

$39(57.4)$

Acute cholecystitis

$20(29.4)$

Chronic cholecystitis

$48(70.6)$

GB carcinoma

$8(11.8)$

Surgical procedures

Open cholecystectomy

$26(38.2)$

Laparoscopic cholecystectomy

$22(32.4)$

Cholecystectomy and biliary tract exploration

$9(13.3)$

Cholecystectomy and partial hepatic wedge resection

Radical correction of GB carcinoma

$5(7.4)$

Rate of conversion from laparoscopic to open surgery

Morbidity

Wound infection

4.2

$3(4.4)$

Bile leakage

Mortality

Median follow-up, years

2

0

$2.8[1-6]$

Values in square brackets indicate ranges and values in parentheses indicate percentages.

cant differences between XGC and GB cancer patients for abdominal pain, fever, jaundice, weight loss, WBC, ALT, total bilirubin and CEA ( $p>0.05$ ), as shown in table 2 .

The radiological findings of the XGC and the coexisting GB cancer group showed focal thickening of the GB wall was more frequent in XGC patients with GB cancer than those without $(\mathrm{p}=0.0117)$. For the $\mathrm{CT}$ enhancement time, early enhancement of the GB was observed more often in patients with GB cancer than those without ( $\mathrm{p}=$ 0.0255). Lymph node enlargement (minimum diameter $>1 \mathrm{~cm}$ ) was seen more often in patients with GB cancer 
Table 2. Comparison of clinical features between XGC patients with and without GB cancer

\begin{tabular}{|c|c|c|c|}
\hline Item & XGC & $\begin{array}{l}\text { XGC with GB } \\
\text { cancer }\end{array}$ & $\mathrm{p}$ value \\
\hline Patients & 62 & 6 & \\
\hline \multicolumn{4}{|l|}{ Symptoms and signs } \\
\hline Abdominal pain & $46(78.0 \%)$ & $2(33.3 \%)$ & 0.1756 \\
\hline Fever & $18(30.5 \%)$ & $1(16.7 \%)$ & 1.0000 \\
\hline Jaundice & $10(16.9 \%)$ & $3(50 \%)$ & 0.0789 \\
\hline Weight loss & $15(25.4 \%)$ & $2(33.3 \%)$ & 0.6352 \\
\hline \multicolumn{4}{|l|}{ Laboratory findings } \\
\hline $\mathrm{WBC} / \mathrm{mm}^{3}$ & $9,326 \pm 2,564$ & $8,321 \pm 2,896$ & 0.5440 \\
\hline ALT, U/l & $75.2 \pm 56.3$ & $64.3 \pm 25.9$ & 0.1260 \\
\hline Total bilirubin, mg/dl & $1.9 \pm 2.3$ & $2.8 \pm 2.6$ & 0.1630 \\
\hline CA19-9 (>37 kU/l) & $22(35.5 \%)$ & $6(100 \%)$ & 0.0034 \\
\hline CEA (positive) & $10(16.1 \%)$ & $2(33.3 \%)$ & 0.2846 \\
\hline \multicolumn{4}{|l|}{ CT scan findings } \\
\hline Maximum thickness of GB wall, mm & $10.5 \pm 4.6$ & $11.2 \pm 3.2$ & 0.1530 \\
\hline Focal thickening of GB wall & $17(27.4 \%)$ & $5(83.3 \%)$ & 0.0117 \\
\hline Heterogeneous enhancement of the GB wall & $39(62.9 \%)$ & $3(50 \%)$ & 0.6827 \\
\hline Early enhancement of GB wall & $21(33.9 \%)$ & $5(83.3 \%)$ & 0.0255 \\
\hline Disrupted mucosal line & $26(41.9 \%)$ & $4(66.7 \%)$ & 0.3937 \\
\hline Intramural hypoattenuated nodule & $32(51.6 \%)$ & $3(50 \%)$ & 1.0000 \\
\hline Gallstone & $35(56.4 \%)$ & $4(66.7 \%)$ & 1.0000 \\
\hline Pericholecystic invasion & $30(48.4 \%)$ & $5(83.3 \%)$ & 0.1978 \\
\hline Lymph node enlargement (>10 mm) & $15(24.2 \%)$ & $4(66.7 \%)$ & 0.0471 \\
\hline \multicolumn{4}{|l|}{ Surgical procedures } \\
\hline Open cholecystectomy & $26(41.9 \%)$ & 0 & 0.0753 \\
\hline Laparoscopic cholecystectomy & $23(37.1 \%)$ & 0 & 0.0892 \\
\hline Cholecystectomy and biliary tract exploration & $9(14.5 \%)$ & 0 & 1.0000 \\
\hline Cholecystectomy and partial hepatic wedge resection & $5(8.1 \%)$ & $1(16.7 \%)$ & 0.4383 \\
\hline Radical correction of GB carcinoma & 0 & $5(83.3 \%)$ & 0.0001 \\
\hline Morbidity & $1(1.6 \%)$ & $2(33.3 \%)$ & 0.1690 \\
\hline Wound infection & 1 & 1 & NA \\
\hline Bile leakage & 0 & 1 & NA \\
\hline
\end{tabular}

Table 3. Multivariate logistic regression analysis for clinical features in XGC patients with GB cancer

\begin{tabular}{lrr}
\hline Item & Odds ratio & $95 \% \mathrm{CI}$ \\
\hline CA19-9 $(>37 \mathrm{kU} / \mathrm{l})$ & 10.256 & $1.665-21.369$ \\
Focal thickening of GB wall & 6.354 & $0.986-10.554$ \\
Early enhancement of GB wall & 9.446 & $1.336-20.559$ \\
Lymph node enlargement $(>10 \mathrm{~mm})$ & 15.677 & $3.999-36.222$ \\
Radical correction of GB carcinoma & 16.846 & $5.221-25.336$ \\
\hline
\end{tabular}

than those without $(p=0.0471)$. There were no significant differences between XGC and GB cancer for maximum thickness of the GB wall, heterogeneous GB enhancement, disrupted mucosal line, intramural hypoattenuated nodule, or accompanied gallstone and pericholecystic invasion, as shown in table 2. Multivariable logistic analysis for GB cancer revealed that CA19-9 (>37 kU/l), focal thickening of the GB wall, early enhancement of the GB wall and lymph node enlargement $(>10 \mathrm{~mm})$ were the independent variables for making the diagnosis of XGC with GB cancer (table 3).

The surgical procedures for the 68 patients are shown in table 1 . Two patients with Mirizzi syndrome that had internal fistula with common bile duct and duodenum 
Table 4. Comparison of patients' clinical data between laparoscopic cholecystectomy and open operation groups

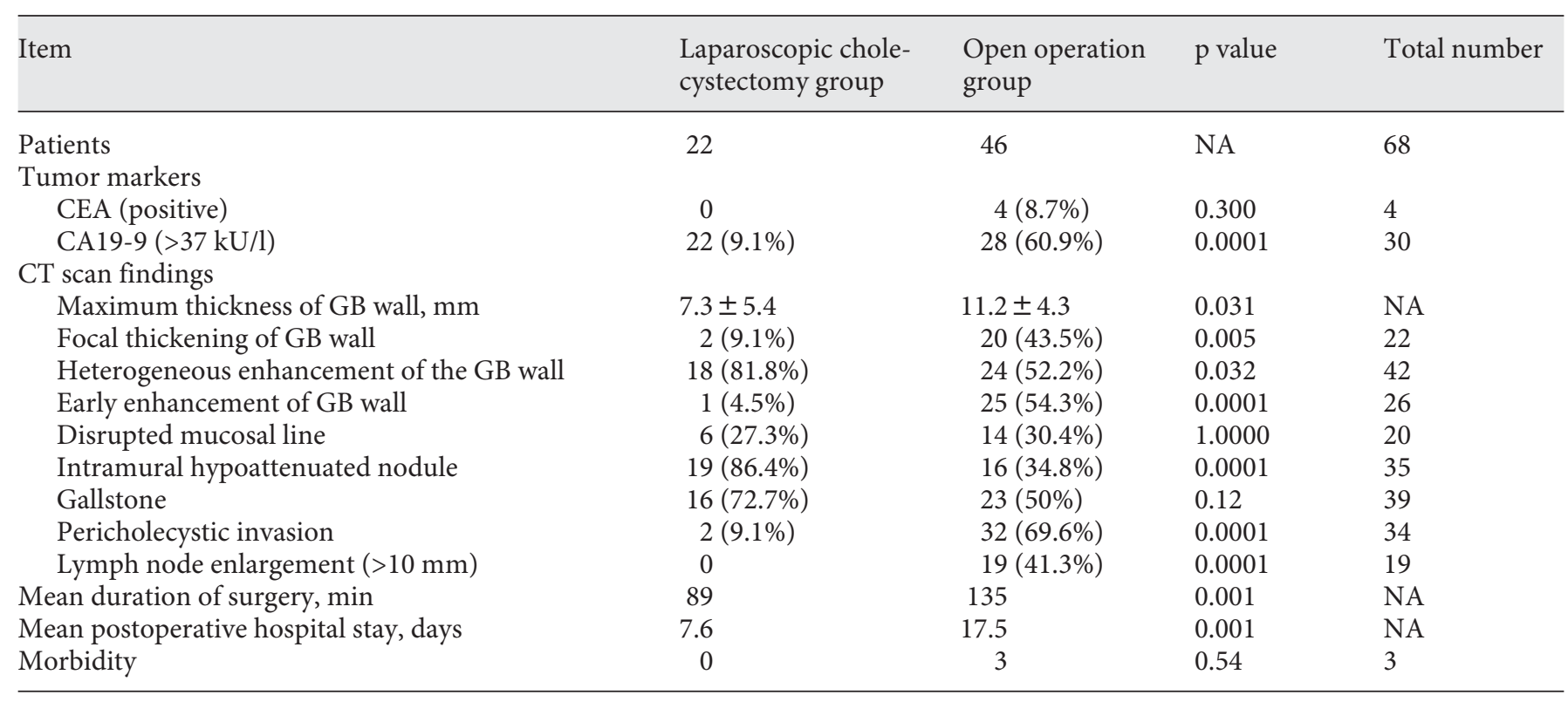

NA = Not applicable

were repaired intraoperatively. Of the 8 patients with suspected carcinoma of the GB preoperatively, 2 were definitively diagnosed with XGC from excised tissue during surgery by frozen section histopathologically. Specimens from all 68 patients were examined pathologically, which indicated that 6 patients had coexisting GB cancer. Complications were observed in 3 patients, including 2 with infection of the incision and 1 patient with bile leakage who recovered 4 weeks after the operation. Follow-up lasted 1-6 years. One patient died of a cardiovascular accident, 1 died of primary kidney carcinoma 1 year after the operation, and 6 patients died of GB cancer. The rest of the patients survived.

The clinical data of laparoscopic cholecystectomy and open surgery are listed in table 4 . There were significant differences between laparoscopic cholecystectomy and laparatomy for CA19-9 ( $\mathrm{p}=0.003)$, maximum thickness of the GB wall ( $p=0.03)$, focal thickening of the GB wall $(p=0.005)$, heterogeneous enhancement of the GB wall $(p=0.03)$, early enhancement of the GB wall $(p=0.0001)$, intramural hypoattenuated nodule $(\mathrm{p}=0.0001)$, pericholecystic invasion $(\mathrm{p}=0.0001)$ and lymph node enlargement $(\mathrm{p}=0.0001)$. The operation time and postoperative hospital stay of the laparoscopic cholecystectomy group were shorter than those of the laparotomy group ( $\mathrm{p}<$ 0.01 ), as shown in table 4. Multivariable logistic analysis for open surgery revealed that CA19-9 ( $>37 \mathrm{kU} / \mathrm{l})$, focal
Table 5. Multivariate logistic regression analysis of clinical features for open surgery

\begin{tabular}{lrl}
\hline Item & Odds ratio & 95\% CI \\
\hline CA19-9 $(>37 \mathrm{kU} / \mathrm{l})$ & 13.264 & $3.332-27.889$ \\
Maximum thickness of GB wall & & \\
$\quad(>10 \mathrm{~mm})$ & 4.776 & $1.227-9.354$ \\
Focal thickening of GB wall & 8.897 & $2.332-15.012$ \\
Early enhancement of GB wall & 18.553 & $9.633-30.959$ \\
Pericholecystic invasion & 8.766 & $3.334-33.863$ \\
Lymph node enlargement $(>10 \mathrm{~mm})$ & 19.654 & $6.122-32.778$ \\
\hline
\end{tabular}

Adjusted for age and sex by binary logistic regression.

thickening of the GB wall, early enhancement of the GB wall, pericholecystic invasion and lymph node enlargement $(>10 \mathrm{~mm}$ ) were the independent variables for making the choice of open surgery (table 5).

\section{Discussion}

In our data, $8.8 \%$ of cases were proven to coexist with GB cancer, $57.4 \%$ coexisted with stones in the GB and $26.5 \%$ had stones stuck in the cyst neck and led to the 
enlargement of the GB. These findings indicate that XGC formation may be associated with gallstones, which is consistent with the report of Kwon et al. [15]. Most of the patients in this study presented with chronic symptoms and signs, as previously reported [16]. Chronic inflammation in XGC always causes persistent thickening of the GB wall and adhesions to adjacent tissues and organs, and in some cases Mirizzi syndrome is found [17], similar to our findings. Another important finding in our study was that elevated CA19-9 correlated with an increased risk of coexistent GB cancer in XGC patients, so CA19-9 may be considered as a marker for coexisting GB cancer.

Some features highly suggestive of XGC on ultrasound and CT have been reported, including thickening of the GB wall, GB stone shadow, and adhesion to neighboring tissues and organs $[18,19]$. Owing to the sensitivity of stones and the thickness of the GB wall, ultrasonographic examination shows some clinical values in diagnosing XGC. These reports are consistent with our findings. Where the lesion was concomitant with a stuck stone, enlargement of the GB and fistula formation, XGC was highly suspected. However, other diseases such as GB cancer or adenomyomatosis also present with wall thickening. Radiological findings of ultrasound and CT were used to differentiate XGC from XGC patients with GB cancer. Focal thickening of the GB wall, early enhancement of the GB wall and lymph node enlargement $(>10 \mathrm{~mm})$ were the independent factors for making a diagnosis of GB cancer. These characteristics could be helpful in making a correct preoperative diagnosis for XGC.

Frozen sections are necessary in patients in whom the differentiation of XGC from malignant lesions is difficult during surgery [20]. From our experience, when lesions had such features as GB wall focal thickening, suspicious invasion and lymph node enlargement, frozen section was preferred. Microscopically, typical granuloma (consisting of flaky foam cells, rhagiocrine cells, fibroblasts, and inflammatory cells) is the gold standard for the pathological diagnosis of XGC $[21,22]$. The appropriate selection of surgery strategy should be based on intraoperative frozen section investigation, which may prevent an unnecessary enlargement of the operation.

Owing to the invasiveness and destruction of XGC, surgery should be performed as soon as the diagnosis of $\mathrm{XGC}$ is made to prevent the occurrence of complications such as fistula [23], which is consistent with our findings. It is also reported that if there is no suspicion of cancer, percutaneous GB drainage may be an efficient method for the initial treatment of severe cases, which gives the opportunity for an elective cholecystectomy with an excellent outcome [24]; there was no such case, however, in our series. In this study, open surgery was still the main surgical procedure for the treatment of XGC. Fistula repairs were performed on 2 patients with Mirizzi syndrome. Special attention should be paid to the dissection of fistula in these cases. In this study, there were 6 patients who had coexisting adenocarcinoma. Of these, 5 underwent radical corrections of GB carcinoma and 1 patient had cholecystectomy and partial hepatic wedge resection because of its early staging, hence the principle for coexisting cancer was still radical surgery.

A comparison between the clinical data of laparoscopic cholecystectomy and open surgery revealed that elevated CA19-9, focal thickening of the GB wall, early enhancement of the GB wall, pericholecystic invasion, lymph node enlargement and fistula formation were characteristic features of open surgery. These features might be helpful for the surgeon in making a correct decision between laparoscopic and open cholecystectomy surgery, as shown in table5. However, laparoscopic cholecystectomy has a shorter operating time and postoperative hospital stay than open surgery, thereby indicating that in some strictly selected cases, laparoscopic surgery has its advantage over open surgery in treating XGC.

Although XGC is a benign disease with a low mortality rate, patients usually have more postoperative complications including leakage of bile, bile peritonitis, bleeding, hepatic abscess, and infection of incision as was observed in only 3 patients in this study. The factors essential for lowering the complication rate may include adequate preoperative evaluation, accurate intraoperative diagnosis, correct choice of surgery and careful surgical manipulation.

\section{Conclusions}

Ultrasound and CT scan were the helpful modalities for preoperative diagnosis. If the malignant situation could not be eliminated, intraoperative frozen section was carried out to differentiate XGC from GB cancer. CA19-9, focal thickening of the GB wall, early enhancement of the GB wall, pericholecystic invasion and lymph node enlargement $(>10 \mathrm{~mm}$ ) were indications for making a decision for open surgery. Open surgery was the main surgical procedure for the treatment of XGC, but for some selected cases laparoscopic cholecystectomy was preferable to open surgery. 


\section{References}

1 Guzman-Valdivia G: Xanthogranulomatous cholecystitis: 15 years experience. World J Surg 2004;28:254-257.

$>2$ Solanki RL, Arora HL, Gaur SK, Anand VK, Gupta R: Xanthogranulomatous cholecystitis (XGC): a clinicopathological study of 21 cases. Indian J Pathol Microbiol 1989;32: 256-260.

3 Tyagi SP, Maheshwari V, Sahoo P, Tyagi N, Ashraf SM: Chronic granulomatous cholecystitis: a clinicopathological study of 17 cases. J Indian Med Assoc 1991;89:284-287.

$\checkmark 4$ Houston JP, Collins MC, Cameron I, Reed MW, Parsons MA, Roberts KM: Xanthogranulomatous cholecystitis. Br J Surg 1994; 81:1030-1032.

$\checkmark 5$ Eriguchi N, Aoyagi S, Tamae T, Kanazawa N, Nagashima J, Nishimura K, Hamada S, Kawabata M, Kodama T: Xanthogranulomatous cholecystitis. Kurume Med J 2001;48: 219-221.

6 Dixit VK, Prakash A, Gupta A, Pandey M, Gautam A, Kumar M, Shukla VK: Xanthogranulomatous cholecystitis. Dig Dis Sci 1998;43:940-942.

-7 Kumar A, Krishnani N, Saxena R, Kapoor VK, Kaushik SP: Xanthogranulomatous cholecystitis. Ind J Gastroenterol 1996;15: 122-125.

8 Rao RV, Kumar A, Sikora SS, Saxena R, Kapoor VK: Xanthogranulomatous cholecystitis: differentiation from associated gall bladder carcinoma. Trop Gastroenterol 2005;26: 31-33.
9 McCoy JJ Jr, Vila R, Petrossian G, McCall RA, Reddy KS: Xanthogranulomatous cholecystitis. Report of two cases. J S C Med Assoc 1976;72:78-79.

10 Guzman-Valdivia G: Xanthogranulomatous cholecystitis in laparoscopic surgery. J Gas trointest Surg 2005;9:494-497.

11 Cárdenas-Lailson LE, Torres-Gómez B, Medina-Sánchez S, Mijares-García JM, Hernández-Calleros J: Epidemiology of xanthogranulomatous cholecystitis (in Spanish). Cir Cir 2005;73:19-23.

12 Afifi El-Sayed M, Juma TH: Primary cystic duct carcinoma. Med Princ Pract 1998;7: 147-149.

13 Kitagawa S, Nakagawa M, Yamada T, Mori Y, Simizu H, Rin S, Kurumaya H: Clinico-pathological study of xanthogranulomatous cholecystitis (in Japanese). Nihon Geka Gakkai Zasshi 1990;91:1001-1010.

14 Roberts KM, Parsons MA: Xanthogranulomatous cholecystitis: clinicopathological study of 13 cases. J Clin Pathol 1987;40:412417.

15 Kwon AH, Matsui Y, Uemura Y: Surgical procedures and histopathologic findings for patients with xanthogranulomatous cholecystitis. J Am Coll Surg 2004;199:204-210.

16 Reaño G, Sanchez J, Ruiz E, Celis J, Payet E, Berrospi F, Chavez I, Young F, Doimi F: Xanthogranulomatous cholecystitis: retrospective analysis of 6 cases (in Spanish). Rev Gastroenterol Peru 2005;25:93-100.

-17 Lee KC, Yamazaki O, Horii K, Hamba H, Higaki I, Hirata S, Inoue T: Mirizzi syndrome caused by xanthogranulomatous cholecystitis: report of a case. Surg Today 1997; 27:757-761.
Kim PN, Ha HK, Kim YH, Lee MG, Kim $\mathrm{MH}, \mathrm{Auh} \mathrm{YH}$ : US findings of xanthogranulomatous cholecystitis. Clin Radiol 1998;53: 290-292.

19 Chun KA, Ha HK, Yu ES, Shinn KS, Kim KW, Lee DH, Kang SW, Auh YH: Xanthogranulomatous cholecystitis: CT features with emphasis on differentiation from gallbladder carcinoma. Radiology 1997;203:9397.

20 Pinocy J, Lange A, König C, Kaiserling E, Becker HD, Kröber SM: Xanthogranulomatous cholecystitis resembling carcinoma with extensive tumorous infiltration of the liver and colon. Langenbecks Arch Surg 2003;388:48-51

21 Hsu C, Hurwitz JL, Schuss A, Katz DS: Radiology-Pathology Conference: xanthogranulomatous cholecystitis. Clin Imaging 2003; 27:421-425.

22 Krishnani N, Dhingra S, Kapoor S, Pandey $\mathrm{R}$ : Cytopathologic diagnosis of xanthogranulomatous cholecystitis and coexistent lesions. A prospective study of 31 cases. Acta Cytol 2007;51:37-41

23 Srinivas GN, Sinha S, Ryley N, Houghton PW: Perfidious gallbladders - a diagnostic dilemma with xanthogranulomatous cholecystitis. Ann R Coll Surg Engl 2007;89:168172 .

24 Psarras K, Baltatzis ME, Symeonidis N, Pavlidis ET, Miha A, Pavlidis TE, Sakantamis AK: A severe case of xanthogranulomatous cholecystitis along with a review of CT indications for nonoperative management including percutaneous drainage. Surg Laparosc Endosc Percutan Tech 2012;22:e42-e44. 